ORIGINAL ARTICLE

\title{
Noninvasive Ventilation-assisted Bronchoscopy in High-risk Hypoxemic Patients
}

\author{
Mrinal Sircar ${ }^{1}$, Onkar K Jha ${ }^{2}$, Gurmeet S Chabbra ${ }^{3}$, Sandip Bhattacharya ${ }^{4}$
}

\begin{abstract}
Background and aims: Hypoxemic patients undergoing fiber-optic bronchoscopy $(\mathrm{FOB})$ are at risk of worsening of respiratory failure requiring mechanical ventilation due to FOB procedure itself and its complications. As patients with respiratory failure are frequently managed by noninvasive ventilation (NIV); feasibility of FOB through NIV mask has been evaluated in some studies to avoid intubation. We describe here our own case series.

Materials and methods: Clinical data of 28 FOB done through NIV mask in 27 intensive care unit (ICU) patients over 6 years period at our center was collected retrospectively and analysed.

Results: Study comprises 27 (17 male; $52 \pm 21.6$ years age) hypoxemic $\left(\mathrm{PaO}_{2} 71.3 \pm 14.2\right.$, on NIV and oxygen supplementation) patients. All FOB were done at bedside, 15 of them were given sedation for the procedure. Twenty four patients had bronchoalveolar lavage (BAL); three underwent bronchial biopsies, four brush cytology and seven transbronchial biopsies. In 10 patients lung or lobar collapse was reversed. There was no significant change between pre and post bronchoscopy ABG parameters except for improved post $\mathrm{FOB} \mathrm{PaO}_{2}(p=0.0032)$ and $\mathrm{SpO}_{2}(p=$ 0.0046). One patient (3.57\%) developed late pneumothorax and 3 patients (10.7\%) had bleeding after biopsy. Prior to bronchoscopy 17 (16 BIPAP, 1 CPAP) patients were already on NIV. Two patients required mechanical ventilation 6 hours after FOB due to subsequent clinical deterioration but could be weaned off later. One patient died on third day after FOB from acute myocardial infarction.

Conclusion: Hypoxemic patients in ICU can safely undergo bedside diagnostic and simple therapeutic bronchoscopy with NIV support while mostly avoiding intubation and with low complication rates.

Keywords: Bronchoscopy, FOB, NIV, Noninvasive ventilation, Respiratory failure

Indian Journal of Critical Care Medicine (2019): 10.5005/jp-journals-10071-23219
\end{abstract}

\section{INTRODUCTION}

Patients with respiratory failure in intensive care unit (ICU) may require fiber-optic bronchoscopy (FOB). However, FOB itself can lead to hypoxemia, hypotension, tracheobronchial bleeding or cardiac arrhythmias. ${ }^{1,2}$ Although empirical treatment is possible, etiological diagnosis is necessary for targeted treatment. ${ }^{3}$ Strategies for microbiological diagnosis may include sputum or endotracheal aspirate examination. In non-intubated patients FOB may be done via laryngeal mask airway ${ }^{4}$ or by intubating them. ${ }^{5}$ These invasive methods may be avoided by using non-invasive ventilation (NIV) during $\mathrm{FOB}^{5-18}$ An alternative technique using high-flow nasal cannula oxygen therapy during FOB is also emerging. ${ }^{19}$

Bronchoscopy with NIV support is relatively less used technique with small number of published papers and only one from India. ${ }^{16}$ We have been using this technique and our experience over a period of six years is presented here. ${ }^{20}$

\section{Materials and Methods}

The study population comprised of 27 patients undergoing 28 bedside FOB procedures on NIV during a period of six years in a medical-surgical ICU. Intent of bronchoscopy was therapeutic in 10 patients with atelectasis (four patients with one lung and six with lobar collapse) that were unresponsive to physiotherapy and was diagnostic in the remaining eighteen.

Of these 28 patients' episodes, 17 were already on NIV (16 on BIPAP and one on CPAP). All these patients were observed to desaturate even with a brief discontinuation ( $<10$ minutes) of NIV and were therefore considered unfit for bronchoscopy off NIV. The patient on CPAP was electively switched to BIPAP for FOB. The

\footnotetext{
1,2Department of Pulmonology and Critical Care, Fortis Hospital, Noida, Uttar Pradesh, India

${ }^{3}$ Department of Respiratory and Sleep Medicine, QRG Central Hospital and Research Centre, Faridabad, Haryana, India

${ }^{4}$ Department of Critical Care, Asian Institute of Medical Sciences, Faridabad, Haryana, India

Corresponding Author: Mrinal Sircar, Department of Pulmonology and Critical Care, Fortis Hospital, Noida, Uttar Pradesh, India, e-mail: mrinalsircar@yahoo.co.uk

How to cite this article: Sircar M, Jha OK, Chabbra GS, Bhattacharya S. Noninvasive Ventilation-assisted Bronchoscopy in High-risk Hypoxemic Patients. Indian J Crit Care Med 2019;23(8):363-367.

Source of support: Nil

Conflict of interest: None
}

remaining 11 patients (included four with lung collapse and rest with diffuse lung diseases) had $\mathrm{PaO}_{2} / \mathrm{FiO}_{2}$ ratio $<300$, respiratory rate $>30$ per min and using accessory muscles of respiration but were not candidates for immediate intubation. These 11 patients were put electively on BIPAP, based on clinical judgement, one hour before FOB.

Noninvasive ventilation was delivered through a tight fitting anaesthesia face mask (Intersurgical Ltd., Berkshire, UK), kept in place using adjustable straps. This mask was then attached to a catheter mount with inbuilt bronchoscopy port, an Oxygen enrichment connector with inbuilt expiratory port (Respironics; Murrysville, PA) and a single limb NIV circuit that was attached to BiPAP-S/T30 machine (BiPAP; Respironics; Murrysville, PA) (Fig. 1). Oxygen was bled into the NIV circuit and flow was adjusted

(c) The Author(s). 2019 Open Access This article is distributed under the terms of the Creative Commons Attribution 4.0 International License (https://creativecommons. org/licenses/by-nc/4.0/), which permits unrestricted use, distribution, and non-commercial reproduction in any medium, provided you give appropriate credit to the original author(s) and the source, provide a link to the Creative Commons license, and indicate if changes were made. The Creative Commons Public Domain Dedication waiver (http://creativecommons.org/publicdomain/zero/1.0/) applies to the data made available in this article, unless otherwise stated. 


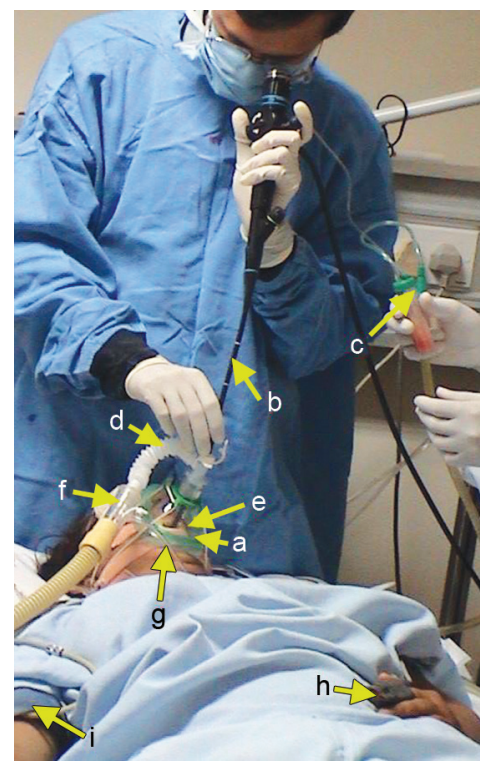

Fig. 1: Fiber-optic bronchoscopy through non-invasive ventilation. (a) Anesthesia face mask; (b) Fiber-optic bronchoscope; (c) Trap for BAL collection; (d) Catheter mount; (e) Bite guard; (f) Oxygen enrichment connector; (g) Oxygen tubing; (h) Pulse oximeter; (i) Noninvasive BP cuff

to keep $\mathrm{SpO}_{2}$ above $90 \%$ during the bronchoscopy procedure. Sixteen patients were already on BIPAP and they continued on their preexisting setting of IPAP of $12-20 \mathrm{~cm} \mathrm{H}_{2} \mathrm{O}$ and EPAP of 4-8 $\mathrm{cm} \mathrm{H}_{2} \mathrm{O}$. For the remaining 12 (including patient on CPAP) patients' initial settings were IPAP of $12 \mathrm{~cm} \mathrm{H}_{2} \mathrm{O}$ and EPAP of four $\mathrm{cm} \mathrm{H}_{2} \mathrm{O}$ and this was adjusted based on clinical response. All patients were also put on a backup rate of 12 breaths per min. Arterial blood gas(ABG) analysis was obtained after one hour when stable clinical parameters were achieved for these 12 patients, as also for all other patients, before proceeding to FOB. ABG was repeated one hour after FOB procedure.

All patients received topical anesthesia (10\% lignocaine throat spray and $2 \%$ lignocaine via bronchoscope). Sedation was used as infusion during 15 bronchoscopies (1\% Propofol in 14 patients and Midazolam in one patient). ${ }^{15}$ All patients had bedside ECG, (noninvasive or arterial) blood pressure and pulse oximetry monitoring during the procedure. A critical care physician provided the sedation and monitored the patient during and after FOB procedure. All bronchoscopies were done by consultant pulmonologists. Bronchoscopy was done through nasal passage in 23 patients and through oral route in five patients (using a bite guard inside the NIV mask). Fiber-optic bronchoscope used (Olympus BF-1T30) had 6.0-mm outer diameter with $2.8 \mathrm{~mm}$ instrument channel. Chest $\mathrm{X}$-ray was done in all patients two hours after FOB procedure.

\section{Results}

Twenty-eight FOB procedures (in 27 patients, 18 males, mean \pm SD age $52 \pm 21.6$ years) were done using NIV support. Demographic details are shown in (Table 1). Indications and results of bronchoscopy are given in (Table 2).

Collapsed lung or lobes were successfully opened up in all 10 patients by repeated saline and $\mathrm{N}$-acetyl cysteine instillations and suctioning. Broncheoalveolar lavage (BAL) samples were obtained
Table 1: Characteristics of study population

\begin{tabular}{ll}
\hline Parameters & Value \\
\hline Age (years) mean \pm SD & $52 \pm 21.6$ \\
Gender $n$ (\%): & \\
Male & $18(64.3)$ \\
Female & $10(35.7)$ \\
Comorbid Illnesses $n(\%):$ & $1(3.57)$ \\
Coronary artery disease & $3(10.7)$ \\
Cerebral vascular accident & $4(14.3)$ \\
Hypertension & $1(3.57)$ \\
Chronic renal failure & $1(3.57)$ \\
Bronchial arthma & $1(3.57)$ \\
Diabetes mellitus & $1(3.57)$ \\
Obstructive sleep apnea & $3(10.7)$ \\
Interstitial lung disease & \\
Immunosupression n(\%): & \\
Malignancy hematological & $1(3.57)$ \\
Malignancy solid organ & $3(10.7)$ \\
Long-term steroid & $4(14.3)$ \\
Reason of respiratory failure $n(\%):$ & \\
Pneumonia & \\
ARDS & $6(21.4)$ \\
Atelectasis & $1(3.57)$ \\
Pulmonary hemorrhage & $14(50)$ \\
Diffuse infiltrates & $2(7.14)$ \\
Type of bronchoscopy $n(\%):$ & $5(15.3)$ \\
Diagnostic & \\
Therapeutic & $18(64.2)$ \\
Use of NIV $n$ (\%): & $10(35.7)$ \\
Preprocedure & \\
Intraprocedure & $16(57.1)$ \\
Postprocedure & $28(100)$ \\
Route of bronchoscopy $n(\%):$ & $19(67.9)$ \\
Nasal & \\
Oral & $23(82.1)$ \\
Postprocedure complication $n(\%):$ & $5(21.7)$ \\
Bleeding & \\
Mechanical ventilation & \\
\hline & \\
&
\end{tabular}

in 24 patients. Bronchial biopsies were done in three patients, brush cytology in four patients and transbronchial biopsies (TBLB) (without using C-arm) in seven patients.

All procedures were well tolerated; no patient needed endotracheal intubation and no hemodynamic instability occurred during FOB. Sedation was well tolerated by patients. Three patients had significant bleeding during FOB that was controlled with bronchoscopic instillation of adrenaline and cold saline. Routine postprocedure chest X-rays after two hours did not reveal any pneumothorax. There was significant improvement in oxygenation noted in post bronchoscopy $A B G s$ in comparison with pre-FOB ABG (Table 3).

All patients on pre-FOB NIV (17 patients) remained on BIPAP afterwards too without requiring intubation. Of the remaining 11 patients, NIV could be discontinued 1-2 hours after FOB in eight patients; one of them developed acute respiratory distress six hours after FOB including TBLB. A repeat chest X-ray revealed a delayed pneumothorax requiring emergent intercostal tube drainage and invasive mechanical ventilation. The patient could be successfully extubated after two days. However, a day later he died of myocardial infarction. This patient had history of myocardial 
Table 2: Indications and results of fiber-optic bronchoscopy

\begin{tabular}{|c|c|c|c|c|c|}
\hline Case \# & FOB Indication & Sedation & Bronchoscopy result & Microorganism & Complication \\
\hline 1 & Atelectasis & No sedation & Infection & Pseudomonas aeruginosa & None \\
\hline 2 & Nodular infiltrates & Propofol & $\begin{array}{l}\text { Infection, neoplasia } \\
\text { (carcinoid) }\end{array}$ & $\begin{array}{l}\text { M. Tuberculosis, Candida } \\
\text { albicans }\end{array}$ & $\begin{array}{l}\text { Late pneumotho- } \\
\text { rax, Mechanical } \\
\text { ventilation }\end{array}$ \\
\hline 3 & Bilateral infiltrates & Propofol & Infection & E. coli & None \\
\hline 4 & $\begin{array}{l}\text { Atelectasis, blunt } \\
\text { trauma abdomen (post- } \\
\text { laparotomy) }\end{array}$ & No sedation & Atelectasis & Stains and culture negative & None \\
\hline 5 & Atelectasis & No sedation & Infection & Proteus mirabilis & None \\
\hline 6 & Atelectasis & Propofol & Infection & Klebsiella pneumoniae & None \\
\hline 7 & $\begin{array}{l}\text { Atelectasis, CRF with } \\
\text { uremic pleural effusion }\end{array}$ & Propofol & Atelectasis & Stains and culture negative & None \\
\hline 8 & Pneumonia & No sedation & Infection, atypical cell & Gram-negative bacilli & Bleeding \\
\hline 9 & Atelectasis & No sedation & Infection, mucous plugging & Klebsiella pneumoniae & None \\
\hline 10 & Atelectasis & No sedation & Infection & Gram-negative bacilli & None \\
\hline 11 & Bilateral infiltrates & Propofol & Infection & $\begin{array}{l}\text { Pseudomonas, GPC, pseudo- } \\
\text { hyphae }\end{array}$ & Bleeding \\
\hline 12 & $\begin{array}{l}\text { Infiltrates, pulmonary } \\
\text { nodule }\end{array}$ & No sedation & $\begin{array}{l}\text { Infection, nonsmall cell } \\
\text { carcinoma }\end{array}$ & Candida albicans & None \\
\hline 13 & Atelectasis & No sedation & Infection, & Candida albicans & None \\
\hline 14 & Atelectasis & Propofol & Infection & E. coli, Klebsiella pneumoniae & None \\
\hline 15 & Atelectasis & Propofol & Infection, mucous plugging & Gram-negative bacilli & None \\
\hline 16 & Pulmonary hemorrhage & Propofol & Chronic inflammation & Stains and culture negative & $\begin{array}{l}\text { Mechanical venti- } \\
\text { lation }\end{array}$ \\
\hline 17 & Atelectasis & No sedation & Infection & Klebsiella pneumoniae & None \\
\hline 18 & Atelectasis & Propofol & Blood clot & Stains and culture negative & None \\
\hline 19 & Pulmonary hemorrhage & Propofol & Interstitial lung disease (UIP) & Stains and culture negative & None \\
\hline 20 & Organizing pneumonia & Propofol & $\begin{array}{l}\text { Interstitial lung disease } \\
\text { (BOOP) }\end{array}$ & Stains and culture negative & None \\
\hline 21 & Pneumonia & Propofol & $\begin{array}{l}\text { Copious secretions in tra- } \\
\text { cheobronchial tree }\end{array}$ & Stains and culture negative & None \\
\hline 22 & ARDS, pneumonia & No sedation & Infection & Pseudomonas aeruginosa & None \\
\hline 23 & Atelectasis & No sedation & Infection & E.coli & None \\
\hline 24 & Pneumonia & No sedation & Infection & Acenetobacter baumannii & Bleeding \\
\hline 25 & Atelectasis & No sedation & Infection & Candida albicans & None \\
\hline 26 & Stridor & Midazolam & Vocal cord edema & Stains and culture negative & None \\
\hline 27 & Organizing pneumonia & propofol & Organizing pneumonia & Stains and culture negative & None \\
\hline 28 & Bilteral infiltrates & propofol & Chronic inflammatory cells & Stains and culture negative & None \\
\hline
\end{tabular}

Table 3: Arterial blood gas parameters pre- and postfiber-optic bronchoscopy

\begin{tabular}{llll}
\hline Parameters & Preprocedure & Postprocedure & Significance \\
\hline $\mathrm{pH}$ & $7.404 \pm 0.0634$ & $7.404 \pm 0.0556$ & 0.3106 \\
$\mathrm{PaCO}_{2}(\mathrm{~mm} \mathrm{Hg})$ & $40.057 \pm 8.528$ & $40.021 \pm 7.198$ & 0.6186 \\
$\mathrm{PaO}_{2}(\mathrm{~mm} \mathrm{Hg})$ & $71.296 \pm 14.160$ & $80.079 \pm 19.400$ & 0.0032 \\
$\mathrm{HCO}_{3}(\mathrm{mmol} / \mathrm{L})$ & $25.396 \pm 5.096$ & $25.064 \pm 4.843$ & 0.5599 \\
$\mathrm{SpO}_{2}(\%)$ & $92.071 \pm 3.761$ & $93.607 \pm 3.881$ & 0.0046 \\
\hline
\end{tabular}

infarction five year back. Final bronchoscopic diagnosis for this patient was pulmonary tuberculosis and atypical carcinoid (Table 2, Case 2). Another patient with diffuse lung disease (Table 2, Case 16), who was put on NIV only for FOB but NIV could not be discontinued afterwards, needed elective mechanical ventilation six hours later due to worsening respiratory distress. He too could be extubated later.

\section{Discussion}

Fiber-optic bronchoscopy is extensively used in ICUs for diagnosis of pulmonary pathology and mucous plugging. However, bronchoscopy is often associated with temporary changes in gas exchange and lung mechanics. ${ }^{21-25}$

Fiber-optic bronchoscope occupies about 10\% of tracheal cross section in nonintubated patients and this can increase work of breathing. ${ }^{26}$ In contrast, a $5.7 \mathrm{~mm}$ bronchoscope occupies $40 \%$ of a $9.0 \mathrm{~mm}$ internal diameter (ID) endotracheal tube and $66 \%$ of a 7.0-mm ID endotracheal tube ${ }^{27}$ potentially increasing the work of breathing even more.

Significant changes in gas exchange parameters occur during FOB, primarily during suctioning. Hypoxemia during or immediately after taking $\mathrm{BAL}$ is most common complication. ${ }^{28} \mathrm{PaCO}_{2}$ increases by about $30 \%$ and $\mathrm{PaO}_{2}$ is decreased by $40 \% .{ }^{21}$ Around $200-300$ $\mathrm{mL}$ of tidal volume is lost during each suctioning period. These 
changes in blood gases result from decrease in lung volumes and loss of functional gas exchange surface during BAL and reflex bronchospasm due to stimulation of vagal receptors in upper airways. Desaturation during bronchoscopy has also been attributed to upper airway collapse that can be reversed by placement of nasopharengeal airway. ${ }^{29}$ The delay before normalization of gas exchange varies from about 15 minutes for normal lungs to several hours in those with parenchymal disease. ${ }^{26,30}$

Significant cardiopulmonary risk has been reported in up to $13 \%$ ventilated patients during bronchoscopy. ${ }^{30}$ The American Thoracic Society recommends avoiding BAL in patients spontaneously breathing with hypercapnia and/or hypoxemia and who cannot be corrected to at least $\mathrm{PaO}_{2}$ of $75 \mathrm{~mm} \mathrm{Hg}$ or to $\mathrm{SpO}_{2}$ more than $90 \%$ with supplemental oxygen. ${ }^{1}$

Noninvasive ventilation has been successfully used for respiratory failure - it decreases work of breathing, improves lung mechanics, recruits closed alveoli, improves blood gases and avoids intubation and mechanical ventilation. ${ }^{7,31}$ As an extension, it has been used to perform FOB in patients with respiratory failure ${ }^{14}$ and it has been to shown to help in improving oxygen saturation and arterial oxygen tension and avoid invasive ventilation. Mechanisms for these are likely to be same as for treatment of respiratory failure with NIV. Further as a corollary with obstructive sleep apnea, NIV is likely to counter upper airway collapse during bronchoscopy. ${ }^{32,33}$ Moreover, as the presence of the bronchoscope within the trachea reduces its caliber and increases airway resistance and work of breathing, application of NPPV may compensate for this extra-work load, thereby improving the tolerability and safety of the bronchoscopic procedure. Small number of studies, mostly observational, have shown successful use of NIV assisted FOB in COPD, ${ }^{6,18}$ immunocompromized patients with pneumonia, ${ }^{5}$ acute respiratory failure with or without pneumonia in ICU, ${ }^{13,15,16,34}$ ARDS patients ${ }^{17,35}$ and non ICU hypoxemic patients. ${ }^{12}$ Few randomized control trials of NIV versus Oxygen supplementation ${ }^{7,8}$ and NIV versus mechanical ventilation ${ }^{13}$ have all reported benefit of from using NIV during FOB. Even upper gastrointestinal endoscopy, ${ }^{36}$ endoscopic retrograde cholangiopancreatography ${ }^{37}$ and transesophageal echocardiography ${ }^{38}$ have been successfully done under NIV support. In yet another study COPD patient in exacerbations with mild encephalopathy and inability to clear secretions were randomized to only NIV versus NIV combined with early FOB for bronchial toileting and latter had superior clinical outcomes. $^{18}$

In our study too all 27 patients could successfully undergo 28 FOB procedure with NIV support without need for immediate intubation. This is one of the largest study evaluating feasibility of FOB in patients on NIV support. All published studies have reported NIV supported FOB guided BAL procedures. Only few studies like Maitre et al. (6 patients) and Chiner et al (eight patients) have reported bronchial biopsies while Agarwal $R$ has reported transbronchial biopsies (six patients) during FOB on NIV support. ${ }^{7,16,34}$ Protected brushing has been reported by Chiner et al. ${ }^{34}$ In our study too we have reported obtaining BAL (24 patients), bronchial (three patients) and transbronchial (seven patients) biopsies as well as brushings (4 patients) safely. ${ }^{20}$ Three patients had significant bleed that was managed successfully while only one patient had (late) pneumothorax.

Two of our patients needed intubation and mechanical ventilation within 24 hours of bronchoscopy as have been reported earlier by other authors. ${ }^{7,8,14,15,17,18}$ The first one needed ventilation after developing a delayed pneumothorax that could be a possible complication of transbronchial biopsy procedure during preceding $\mathrm{FOB}$ or simply due to the underlying disease (pulmonary tuberculosis with atypical carcinoid) itself. The patient could be successfully extubated two days later after complete resolution of pneumothorax and resultant respiratory deterioration. The second patient needing mechanical ventilation after $F O B$ had bilateral lung contusion after a road traffic accident and had only been subjected to BAL. Worsening of gas exchange is well known after BAL, ${ }^{21,28}$ which may or may not be prevented or reversed by application of NIV. This patient too could be extubated later.

Overall there was improvement in oxygenation although FOB can adversely affect it, perhaps due to inclusion of 10 patients who had resolution of their lung/lobe collapse.

All our patients were admitted in ICU. Bronchoscopy was therapeutic for 10 patients as they succeeded in opening up atelectatic areas. In 18 remaining instances FOB was primarily diagnostic in intent. Except for a few studies ${ }^{11,12}$ others too have done FOB with NIV support only for ICU patients.

We used sedation for 15 of 28 FOB procedures and it was well tolerated as has been reported by others in hypoxemic patients in general $^{39}$ and during NIV supported FOB. ${ }^{15,40}$

Different interfaces have been used for FOB on NIV support including oro-nasal mask, ${ }^{5,8,16,17}$ full face mask, ${ }^{14,18}$ nasal mask with bite block covered by glove finger through which FOB is introduced, ${ }^{10,34}$ helmet mask ${ }^{9}$ modified total face mask ${ }^{12}$ and Boussignac CPAP coupled to a face mask. ${ }^{7}$ No study till date has compared different types of masks.

We used a dedicated NIV device (BiPAP-ST) for our FOB procedures. Other studies have reported using either ICU ventilators to deliver $\mathrm{NIV}^{5,8,13,14,16,17}$ or dedicated NIV devices ${ }^{17,34}$ or even Boussignac CPAP device. ${ }^{7}$ All approaches seem to work equally well though no study has tried to compare different NIV devices.

Our study has shown that NIV can facilitate both diagnostic and therapeutic bronchoscopic procedures in selected hypoxemic ICU patients while mostly avoiding intubation. Not only BAL but biopsies and brushing could be done safely. Close monitoring of vital signs is required both before initiation of $\mathrm{FOB}$ and for extended periods afterwards as late complications can occur. All bronchoscopies were however performed by experienced pulmonologists while being monitored by intensivists with combined expertise to manage complications of FOB.

\section{References}

1. Goldstein RA, Rohatgi PK, Bergofsky EH, Block ER, Daniele RP, Dantzker DR, et al. Clinical role of bronchoalveolar lavage in adults with pulmonary disease. Am.Rev.Respir.Dis. 1990;142:481-486.

2. Shelhamer JH, Toews GB, Masur H, Suffredini AF, Pizzo PA, Walsh TJ, et al. NIH conference. Respiratory disease in the immunosuppressed patient. Ann.Intern.Med. 1992;117:415-431.

3. Sircar M, Ranjan P, Gupta R, Jha OK, Gupta A, Kaur R, et al. Impact of bronchoalveolar lavage multiplex polymerase chain reaction on microbiological yield and therapeutic decisions in severe pneumonia in intensive care unit. J.Crit.Care 2016;31:227-232.

4. Hilbert G, Gruson D, Vargas F, Valentino R, Favier JC, Portel L, et al. Bronchoscopy with bronchoalveolar lavage via the laryngeal mask airway in high-risk hypoxemic immunosuppressed patients. Crit. Care Med. 2001;29:249-255.

5. Antonelli M, Conti G, Riccioni L, Meduri GU. Noninvasive positivepressure ventilation via face mask during bronchoscopy with BAL in high-risk hypoxemic patients. Chest 1996;110:724-728. 
6. Da Conceicao M, Genco G, Favier JC, Bidallier I, Pitti R. Fiberoptic bronchoscopy during noninvasive positive-pressure ventilation in patients with chronic obstructive lung disease with hypoxemia and hypercapnia. Ann.Fr.Anesth.Reanim. 2000;19:231-236.

7. Maitre B, Jaber S, Maggiore SM, Bergot E, Richard JC, Bakthiari H, et al. Continuous positive airway pressure during fiberoptic bronchoscopy in hypoxemic patients. A randomized double-blind study using a new device. Am.J.Respir.Crit.Care Med. 2000;162:1063-1067.

8. Antonelli M, Conti G, Rocco M, Arcangeli A, Cavaliere F, Proietti R, et al. Noninvasive positive-pressure ventilation vs. conventional oxygen supplementation in hypoxemic patients undergoing diagnostic bronchoscopy. Chest 2002;121:1149-1154.

9. Antonelli M, Pennisi MA, Conti G, Bello G, Maggiore SM, Michetti V, et al. Fiberoptic bronchoscopy during noninvasive positive pressure ventilation delivered by helmet. Intensive Care Med. 2003;29:126-129.

10. Chiner E, Llombart M, Signes-Costa J, Andreu AL, Gomez-Merino $E$, Pastor $E$, et al. Description of a new procedure for fiberoptic bronchoscopy during noninvasive ventilation through a nasal mask in patients with acute respiratory failure. Arch.Bronconeumol. 2005;41:698-701.

11. Trachsel D, Erb TO, Frei FJ, Hammer J, Swiss Paediatric Respiratory Research Group. Use of continuous positive airway pressure during flexible bronchoscopy in young children. EurRespirJ. 2005;26:773777.

12. Heunks LM, de Bruin CJ, van der Hoeven JG, van der Heijden HF. Non-invasive mechanical ventilation for diagnostic bronchoscopy using a new face mask: an observational feasibility study. Intensive Care Med. 2010;36:143-147.

13. Scala R, Naldi M, Maccari U. Early fiberoptic bronchoscopy during non-invasive ventilation in patients with decompensated chronic obstructive pulmonary disease due to community-acquiredpneumonia. Crit.Care 2010;14:R80.

14. Baumann HJ, Klose H, Simon M, Ghadban T, Braune SA, Hennigs JK, et al. Fiber optic bronchoscopy in patients with acute hypoxemic respiratory failure requiring noninvasive ventilation--a feasibility study. Crit.Care 2011;15:R179.

15. Clouzeau B, Bui HN, Guilhon E, Grenouillet-Delacre M, Leger MS, Saghi $T$, et al. Fiberoptic bronchoscopy under noninvasive ventilation and propofol target-controlled infusion in hypoxemic patients. Intensive Care Med. 2011;37:1969-1975.

16. Agarwal R, Khan A, Aggarwal AN, Gupta D. Bronchoscopic lung biopsy using noninvasive ventilatory support: case series and review of literature of NIV-assisted bronchoscopy. Respir.Care 2012;57:19271936.

17. Korkmaz Ekren P, Basarik Aydogan B, Gurgun A, Tasbakan MS, Bacakoglu F, Nava S. Can fiberoptic bronchoscopy be applied to critically ill patients treated with noninvasive ventilation for acute respiratory distress syndrome? Prospective observational study. BMC PulmMed. 2016;16:89,016-0236-y.

18. Rady W, Abouelela A, Abdallah A, Youssef W. Role of bronchoscopy during nonivasive ventilation in hypercapnic respiratory failure. Egypt J Chest Dis Tuberc 2014;63:1003-1011.

19. Simon M, Braune S, Frings D, Wiontzek AK, Klose H, Kluge S. Highflow nasal cannula oxygen versus non-invasive ventilation in patients with acute hypoxaemic respiratory failure undergoing flexible bronchoscopy--a prospective randomised trial. Crit.Care 2014;18:712,014-0712-9.

20. Sircar M, Chabbra GS, Bhattacharya S. Bronchoscopy in Hypoxemic ICU Patients using Noninvasive Ventilation. Critical Care Med 2008;36:A133.

21. Lindholm CE, Ollman B, Snyder JV, Millen EG, Grenvik A. Cardiorespiratory effects of flexible fiberoptic bronchoscopy in critically ill patients. Chest 1978;74:362-368.
22. Albertini R, Harrel JH, Moser KM. Letter: Hypoxemia during fiberoptic bronchoscopy. Chest 1974;65:117-118.

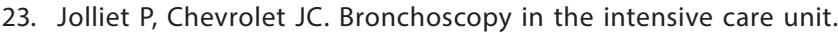
Intensive Care Med. 1992;18:160-169.

24. Lindholm CE, Ollman B, Snyder J, Millen E, Grenvik A. Flexible fiberoptic bronchoscopy in critical care medicine. Diagnosis, therapy and complications. Crit.Care Med. 1974;2:250-261.

25. Matsushima $Y$, Jones RL, King EG, Moysa G, Alton JD. Alterations in pulmonary mechanics and gas exchange during routine fiberoptic bronchoscopy. Chest 1984;86:184-188.

26. Zavala D. Bronchoscopy, lung biopsy, and other procedures. In: Murray J, Nadel J, editors. Textbook of respiratory medicine Philadelphia London Toronto Montreal Sydney tokyo: Saunders; 1988. p. 562-595.

27. Campos JH. Fiberoptic bronchoscopy guidelines for the anesthesiologist. Revista Mexicana de Anestesiología 2011;31:S264-9.

28. Barrett CR,Jr, Vecchione JJ, Bell AL,Jr. Flexible fiberoptic bronchoscopy for airway management during acute respiratory failure. Am.Rev. Respir.Dis. 1974;109:429-434.

29. Chhajed PN, Aboyoun C, Malouf MA, Hopkins PM, Plit M, Grunstein RR, et al. Management of acute hypoxemia during flexible bronchoscopy with insertion of a nasopharyngeal tube in lung transplant recipients. Chest 2002;121:1350-1354.

30. Trouillet JL, Guiguet M, Gibert C, Fagon JY, Dreyfuss D, Blanchet F, et al. Fiberoptic bronchoscopy in ventilated patients. Evaluation of cardiopulmonary risk under midazolam sedation. Chest 1990;97:927933.

31. Schlobohm RM, Falltrick RT, Quan SF, Katz JA. Lung volumes, mechanics, and oxygenation during spontaneous positive-pressure ventilation: the advantage of CPAP over EPAP. Anesthesiology 1981;55:416-422.

32. Borowiecki B, Pollak CP, Weitzman ED, Rakoff S, Imperato J. Fibrooptic study of pharyngeal airway during sleep in patients with hypersomnia obstructive sleep-apnea syndrome. Laryngoscope 1978;88:1310-1313.

33. Popper RA, Leidinger MJ, Williams AJ. Endoscopic observations of the pharyngeal airway during treatment of obstructive sleep apnea with nasal continuous positive airway pressure--a pneumatic splint. West.J.Med. 1986;144:83-85.

34. Chiner E, Sancho-Chust JN, Llombart M, Senent C, Camarasa A, Signes-Costa J. Fiberoptic bronchoscopy during nasal non-invasive ventilation in acute respiratory failure. Respiration 2010;80:321-326.

35. Bove T, Votta CD, Ciriaco P, Papalardo F, Oriani A, Frau G, et al. Bronchoscopy during non-invasive ventilation in a patient with acute respiratory distress syndrome. SIGNA VITAE 2017;13:103-104.

36. Cabrini L, Nobile L, Cama E, Borghi G, Pieri M, Bocchino S, et al. Noninvasive ventilation during upper endoscopies in adult patients. A systematic review. Minerva Anestesiol. 2013;79:683-694.

37. Folgado MA, De la Serna C, Llorente A, Rodriguez S, Ochoa C, DiazLobato $S$. Utility of noninvasive ventilation in high-risk patients during endoscopic retrograde cholangiopancreatography. Lung India. 2014;31:331-335.

38. Guarracino F, Cabrini L, Baldassarri R, Cariello C, Covello RD, Landoni $\mathrm{G}$, et al. Non-invasive ventilation-aided transoesophageal echocardiography in high-risk patients: a pilot study. Eur.J.Echocardiogr. 2010;11:554-556.

39. Dreher M, Ekkernkamp E, Storre JH, Kabitz HJ, Windisch W. Sedation during flexible bronchoscopy in patients with pre-existing respiratory failure: Midazolam versus Midazolam plus Alfentanil. Respiration 2010;79:307-314.

40. Hilbert G, Clouzeau B, Nam Bui H, Vargas F. Sedation during noninvasive ventilation. Minerva Anestesiol. 2012;78:842-846. 